\title{
ВЛИЯНИЕ БАНКОВСКОЙ СИСТЕМЫ НА ЭКОНОМИЧЕСКУЮ БЕЗОПАСНОСТЬ СТРАНЫ
}

Мусханова Х.Ж.

ФГБОУ ВО «Чеченский государственный университет», г. Грозный, Россия

В данной статье исследуются проблемь взаимодействия банковской системы и реального сектора экономики, а также их влияние на экономическую безопасность страны. Изучены и идентифицированы критерии устойчивости банковской системьл. Исследованы трактовки понятия «экономическая безопасность» с позичии мнений разных ученых, установлена причинно-следственная связь банковской системь и реального сектора экономики регионов, предложен ряд мер, способствующих созданию возможностей для сбалансированного развития банковского сектора и реальной экономики.

Ключевые слова: экономическая безопасность, банковская система, устойчивость банковской системы, реальный сектор экономики.

Актуальность темы исследования обусловлена тем, что экономическая безопасность страны занимает одно из центральных мест в вопросах национальной безопасности страны. Это объясняется тем, что воздействие экономической сферы на другие имеет большую значимость, чем влияние этих сфер на нее. Это связано с тем, что экономическая сфера является основополагающей и определяет систему жизнеобеспечения прочих сфер.

Для удержания позиции, занимаемой Россией на мировой арене, необходимо устойчивое развитие экономики, а также создание благоприятных условий для ее дальнейшего развития.

Исследованию теоретических аспектов экономической безопасности посвящено большое количество трудов отечественных ученых.

Так, с точки зрения академика Л. А. Абалкина, экономическая безопасность - это совокупность условий и факторов, обеспечивающих независимость национальной экономики, ее стабильность и устойчивость, способность к постоянному обновлению и самосовершенствованию [1].

И.Я. Богданов определяет термин «экономическая безопасность» как «состояние экономики страны, которое, во-первых, по объемным и структурным параметрам достаточно для обеспечения существующего статуса государства, его независимого от внешнего давления политического и социально-экономического развития и, во-вторых, способно поддерживать уровень легальных доходов, обеспечивающий абсолютному большинству населения благосостояние, соответствующее стандартам цивилизованных стран» [2] 
Таким образом, экономическую безопасность можно определить, как достижение такого состояния экономики, которое будет обеспечивать достаточно высокий устойчивый экономический рост, эффективное удовлетворение экономических потребностей, контроль государства за движением и использованием национальных ресурсов, защита экономических интересов страны на национальном и международном уровнях. [3]

На современном этапе рыночной экономики обеспечение экономической безопасности является главной функцией государственного аппарата, так как экономическая безопасность неразрывно связана с национальной безопасностью, где ключевым фактором выступает банковская система.

Банковская система Российской Федерации занимает особое место в финансовой системе страны и является центральным звеном всех экономических отношений. Банковская система, являясь составной частью финансовой системы, тесно связана с экономикой и ее отраслями. Она включена в инфраструктуру, обслуживающую реальное производство, и поэтому в значительной степени зависит от уровня развития реального сектора, одновременно и сама, оказывая сильное воздействие на экономику.

К сожалению, российская банковская система находится на недостаточном уровне развития по сравнению с развитыми странами, что усиливает негативное влияние постоянно возникающих экономических угроз. Успешная же работа банковской системы определяет стабильность в экономической, а также политической обстановки в целом [10]. Именно устойчивая банковская система выполняет уникальные функции системообразования деятельности всех субъектов экономических отношений по получению банковских услуг.

Устойчивость банковской системы означает прочную связь между всеми ее элементами. При нарушении устойчивости банковской системы, при нарушении безопасности внутри нее самой, при ее недостаточной развитости, она сама может явиться угрозой экономической безопасности страну.

Поэтому в зарубежной практике уделяется особое внимание проблемам модернизации методов оценки устойчивости банков. По отношению к банковской системе, устойчивость предполагает такие критерии, как:

1. Наличие позитивной тенденции.

2. Отражение через активное количественное увеличение объемов не только экономической, но и собственно финансовой области экономики.

3. Сбалансированность показателей всех элементов банковской структуры, в т.ч. - капитала, финансов, резервов прибыли.

4. Рост не только количественный по укрупнению своей деятельности, но и рост, обеспечивающий вектор оптимизации её качества.

5. Наличие основания для дальнейшего бесконечного развития.

6. Равновесие в развитии базовых элементов банковской деятельности, сопровождающееся диверсификацией портфеля банковских инвестиции и понижением значений специфических банковских рисков. 
7. Реализация равновесия среди разных элементов банковской деятельности [7].

Таким образом, устойчивая банковская система является неотъемлемой частью динамично развивающейся экономики страны. Несостоятельные банки, в свою очередь, представляют угрозу не только всему банковскому сектору, но и на прямую оказывают влияние на реальный сектор экономики, который является основой национальной экономики. Влияние на экономику банки оказывают посредством осуществления своих функций: привлечение и накопление временно свободных денежных средств, посредничество в кредитовании, посредничество в проведении расчетов и платежей, создание кредитных денег и т.д.

Основные задачи банковской системы заключаются в том, чтобы обеспечить «здоровое» функционирование экономики, что детерминирует высокую степень корреляции экономической безопасности страны от состояния экономической безопасности банковского сектора.

Банковский сектор более уязвим и подвержен рискам в большей степени по сравнению с другими отраслями. Это связано, прежде всего, с тем, что банки несут риск финансовых потерь: потерь собственных средств, недополучения доходов, дополнительные расходы в результате определенных финансовых операций.

Экономическая безопасность банка определяется рядом факторов:

- наличие конкурентоспособной среды на рынке банковских услуг;

- механизм регулирования по контролю и надзору за деятельностью коммерческих банков со стороны Центрального банка;

- уровень развития национальной экономики страны;

- влияние внешних и внутренних источников финансирования на уровень развития банковской системы;

- стабильность национальной валюты [4].

В связи с этим возрастает роль обеспечения безопасности банковской системы регионов, которая является структурными элементами всей банковской системы страны.

Функционирование банковской системы можно считать эффективным тогда, когда банки взаимодействуют с реальным сектором экономики, а именно оказывают влияние на пути экономического развития реального сектора экономики [12]. Непосредственное влияние - это банковские кредиты. Участие банков в инвестиционных процессах способствуют созданию благоприятных условий для деятельности субъектов хозяйствования, а также оказывают стабилизирующее влияние на экономическую ситуацию в целом. И здесь приоритетной является задача по развитию реального сектора, ориентированного главным образом на внутренний рынок. Сбалансированность банковского сектора с реальным сектором экономики будет обеспечивать устойчивое экономическое развитие страны, эффективность взаимодействия которых определяется наличием благоприятного инвестиционного климата. В настоящее время актуальность проблемы взаимодействия банковской системы 
и ее влияние на экономический рост реального сектора экономики обусловлена рядом факторов. Одним из них является недостаточное участие банков в краткосрочном кредитовании предприятий, что является тормозом на пути экономического развития реального сектора экономики страны [5].

По оценкам экспертов, потребность малого предпринимательства в кредитных средствах удовлетворена лишь на 20-30\%. Так как малый бизнес в основном нуждается в небольших, по сравнению со средним и крупным бизнесом, суммах, при этом риск невыполнения обязательств по кредитам у такого рода бизнеса значительно выше. Поэтому многие банки неохотно хотят взаимодействовать с ними, многие даже отказывают в выдаче кредита, так как помимо всего прочего малый бизнес часто сталкивается с проблемой залога - и им просто нечего предложить банку. Тем не менее, в первом квартале 2019 года в целом по России наблюдался рост $(10,2 \%)$ объемов кредитования МСП, по сравнению с 2018 годом: 1,54 трлн. рублей и 1,4 млрд. рублей. Это говорит о том, что инвестиционная активность банков растет, хоть и медленно, но растет [6]. Сравнительные показатели предоставляемых кредитов МСП по Российской Федерации представлены в таблице 1. Исходя из данных таблицы, мы видим, что в некоторых регионах наблюдается положительная динамика инвестиционной активности. Например, анализ данных по Центральному федеральному округу показывает, что объемы за анализируемый период растут, если в 2018 году задолженность по кредитам составила 12350,9 млрд. рублей, то в 2019 году она увеличилась на 13,8 \%, что составило 14333,7 млрд. рублей. Низкие показатели задолженности мы видим по Северо-Кавказскому, Приволжскому, Сибирскому федеральным округам, что говорит о недоиспользовании потенциала кредитных отношений. Сложившаяся ситуация является тормозом на пути развития реального сектора экономики данных регионов.

Таблица 1 - Задолженность по кредитам в рублях, представленным кредитными организациями МСП (исходя из местонахождения заемщиков; на начало года; млрд. рублей) [8]

\begin{tabular}{|c|c|c|c|c|c|c|c|}
\hline & 2013 г. & 2014 г. & 2015 г. & 2016 г. & 2017 г. & 2018 г. & 2019 г. \\
\hline $\begin{array}{c}\text { Российская } \\
\text { Федерация }\end{array}$ & 16142,5 & 17963,3 & 20659,5 & 20888,9 & 21731,6 & 22880 & 25760,8 \\
\hline $\begin{array}{c}\text { Центральный } \\
\text { федеральный } \\
\text { округ }\end{array}$ & 8299,2 & 9181,6 & 10722,6 & 10756,6 & 11565,6 & 12350,9 & 14333,7 \\
\hline $\begin{array}{c}\text { Северо-Западный } \\
\text { федеральный } \\
\text { округ }\end{array}$ & 1793,5 & 1992,6 & 2245,3 & 2188,8 & 2055,8 & 2199,6 & 2576,3 \\
\hline $\begin{array}{c}\text { Южный } \\
\text { федеральный } \\
\text { округ }\end{array}$ & 1052,9 & 1187,8 & 1284 & 1260,7 & 1307,8 & 1451,4 & 1583,1 \\
\hline $\begin{array}{c}\text { Северо- } \\
\text { Кавказский } \\
\text { федеральный } \\
\text { округ }\end{array}$ & 250,5 & 292,8 & 307,4 & 311,4 & 303,8 & 306,5 & 292,3 \\
\hline
\end{tabular}




\begin{tabular}{|c|c|c|c|c|c|c|c|}
\hline $\begin{array}{c}\text { Приволжский } \\
\text { федеральный } \\
\text { округ }\end{array}$ & 2095,7 & 2322,9 & 2633,1 & 2601,7 & 2558,7 & 2536,1 & 2481,3 \\
\hline $\begin{array}{c}\text { Уральский } \\
\text { федеральный } \\
\text { округ }\end{array}$ & 1042,8 & 1230 & 1439,1 & 1709,5 & 1647,7 & 1743,5 & 2046,6 \\
\hline $\begin{array}{c}\text { Сибирский } \\
\text { федеральный } \\
\text { округ }\end{array}$ & 1123,4 & 1192,3 & 1417,9 & 1490,6 & 1685,4 & 1633,1 & 1678,4 \\
\hline $\begin{array}{c}\text { Дальневосточный } \\
\text { федеральный } \\
\text { округ }\end{array}$ & 484,2 & 563,1 & 609,7 & 569,2 & 606,7 & 658,5 & 768,7 \\
\hline
\end{tabular}

Примечание: Составлено автором на основе официальных источников информации: Официальный сайт Федеральная служба государственной статистики [электронный ресурс]. Режим доступа: https://www.gsk.ru

Изучая проблемы участия банковской системы в решении задач экономического развития регионов, необходимо четко определить ее место в экономике. Так как параметры, характеризующие развитие банковского сектора региона, находятся в тесной взаимосвязи с показателями общего экономического развития. $\mathrm{B}$ регионах с низким уровнем развития первостепенную роль в обеспечении эффективного экономического развития должно играть создание возможностей для сбалансированного развития банковского сектора и реальной экономики. В настоящее время эта проблема актуальна для многих регионов Российской Федерации [11].

Развитию кредитных отношений на региональном уровне будут способствовать:

- проведение политики по снижению среднего уровня формирования процентных ставок;

- разработка механизма дифференцированного регулирования процентной политики кредитных организаций в регионах;

- разработка специализированных лицензий для стимулирования промышленного развития предприятий;

- формирование конкурентной среды на рынке банковских услуг в регионах.

Таким образом, следует отметить, что пока банковская система, несмотря на положительную динамику большинства показателей, не реализовала себя полностью в инвестиционном процессе. Необходимо также отметить, что взаимодействие банковского сектора с реальным сектором экономики в первую очередь определяется объективными экономическими условиями, в которых будет развиваться банковская система, отсюда следует, что Банк России должен проводить стимулирующую политику, а также разработать механизм дифференцированного регулирования кредитных организаций в регионах. Так как развитие российских регионов на достаточно качественном уровне будет оказывать стабилизирующее влияние на экономику в целом [9].

Таким образом, положительное развитие устойчивости банковской системы и ее взаимодействие с реальным сектором в обеспечении «здорового» 
функционирования экономики определяет высокую степень зависимости экономической безопасности от состояния банковской системы.

Несмотря на достаточное количество исследований, данная проблема не теряет актуальности и требует постоянного углубления, что объясняется изменчивостью характера самой банковской системы, которая требует к себе постоянного научного внимания.

\section{Исследование выполнено при финансовой поддержке РФФИ в рамках научного проекта № 19-310-90035/19.}

\section{Список литературы:}

1. Абалкин Л. А. Экономическая безопасность России: угрозы и их отражение // Вопросы экономики. 1994. № 12. с. 10-29.

2. Богданов И.Я. Экономическая безопасность России: теория и практика. - М.: ИСПИ РАН, 2001

3. Белоглазова Г.Н. Стратегия развития регионального сегмента банковской экспансии. Банковское дело «2» 2011. с - 74-78

4. Гребеник В. В., Бушуева Н. В. Системный взгляд на экономическую безопасность государства // Вестник Московского университета имени С. Ю. Витте. Серия 1: Экономика и управление. 2013. № 1 (3). С. 29-32.

5. Демильханова Б.А., Мусханова Х.Ж., Тапаев Р.В. Участие банков в воспроизводстве основного капитала промышленных предприятий Чеченской республики. International Scientific Conference «Social and Cultural Transformations in the Context of Modern Globalism». 2020 г.

6. Казаренкова Н.П., Остимук О.В. Стратегия эффективного взаимодействия коммерческих банков и предприятий реального сектора экономики // Научный альманах Центрального Черноземья. 2014. № 2. С. $117-$ 121.

7. Мусханова Х.Ж. Инструменты и подходы в оценке устойчивости банковской системы РФ. ВАК журнал. «Ученые записки Крымского инженерно-педагогического университета - 2019 № 4 (66)». 2019 - с. 218

8. Официальный сайт Центральный банк Российской Федерации. [Электронный ресуpc]: URL: http://www.cbr.ru/.

9. Тарасова, О. Е. Анализ влияния коммерческих банков на развитие реального сектора экономики / Проблемы современной экономики: материалы II Междунар. науч. конф. (г. Челябинск, октябрь 2012 г.). — Челябинск: Два комсомольца, 2012. - с. 112-114.

10. Тавбулатова 3.К., Таштамиров М.Р. Институциональные особенности структуры и проблемы устойчивости банковской системы России на современном этапе // Российский экономический интернет-журнал. - 2017.- № 1. - C. 36 . 
11. Тавбулатова 3.К., Таштамиров М.Р. Значение региональных банков //Ученые записки Крымского инженерно-педагогического университета. 2017.- № 3 (57). - С. 65-69.

12. Цапиева О.К. Проблемы взаимодействия банковской системы и экономики региона: вопросы теории. Финансовая политика и бюджетное регулирование экономики региона. 2010. -с. 174. 